\title{
Spontaneous resolution of syringohydromyelia in a case of spinal Perimedullary Arteriovenous fistula (Type IVA) associated with low lying tethered cord
}

\author{
Vivek Singh*, Shamick Biswas, Suprava Naik, Phadke RV and Zafar Neyaz \\ Department of Radiology, Sanjay Gandhi Post Graduate Institute of Medical Sciences (SGPGIMS), Lucknow, Uttar Pradesh, India
}

\begin{abstract}
Introduction: Perimedullary arteriovenous fistulas (PMAVF) are defined as direct fistulous connections located on the pial surface of the spinal cord, between the anterior and/or posterior spinal arteries and the medullary veins, without any intervening nidus. PMAVFs constitute about 4\% to 38\% of all SCAVMs and are rare in children. The association of syringohydromyelia with low lying tethered cord in a case of PMAVF with spontaneous resolution of the syrinx has not been previously described in literature.

Case report: Here we report the case of a 6 year old male child who presented with rapidly progressive weakness of both the lower limbs without any obvious sensory loss or bladder/bowel dysfunction. MRI of the spine revealed low lying tethered cord (lower border ending at the level of S3) with cord expansion and long segment septated syrinx (extending from lower border of D7 to S3). Long segment non-enhancing T2 hyper intensity was also noted in the upper dorsal cord. Multiple tortuous flow voids were seen on the surface of the cord, predominantly at its ventral aspect. Digital subtraction angiography (DSA) revealed a PMAVF (Type IVA SCAVM) with a single arterial feeder from left D9 intercostal artery. Repeat MRI done two months later showed marked spontaneous resolution of the syrinx in the dorsal region with persistence of the perimedullary flow voids. Clinically there was symptomatic improvement with resolution of the paraparesis and increased power in both the lower limbs.
\end{abstract}

Conclusion: The association of syringohydromyelia in a case of type IVA PMAVF with low lying tethered cord in a child and its spontaneous resolution with clinical and radiological improvement has not been previously described in literature. The constellation of all these findings prompted us to report this rare entity.

\begin{abstract}
Abbreviations: MRI: Magnetic Resonance Imaging; DSA: Digital Subtraction Angiography; PMAVF: Perimedullary arteriovenous fistula; SCAVM: Spinal cord arteriovenous malformation

\section{Introduction}

Spinal cord arteriovenous malformations (SCAVMs) are relatively rare lesions and account for $3 \%$ to $12 \%$ of spinal space-occupying lesions. Only $13 \%$ of all cases of SCAVMs reported in various series were under 20 years of age [1]. SCAVMs may be classified into four types: type-I SCAVMs are dural arteriovenous fistulas (AVFs); type - II and type-III SCAVMs are arteriovenous malformations (AVMs) glomus and juvenile respectively and type-IV SCAVMs are intradural and extra medullary so called perimedullary arteriovenous fistulas (PMAVFs). Patients suffering from PMAVFs are usually diagnosed in the $2^{\text {nd }}$ or $3^{\text {rd }}$ decade of life. The estimated prevalence of PMAVFs in the paediatric population is around $0.5 \%$ to $3.25 \%$. Presentation in the first 2 years of life is exceedingly rare [1].
\end{abstract}

Syringomyelia is the presence of a cavity in the spinal cord and was first used by Ollivier d'Angers in 1827 [2]. Low lying tethered cord is defined as the tip of the conus medullaris lying below L2 with thickened filum terminale ( $>2 \mathrm{~mm}$ at the level of L5-S1) due to tethering [3].

The association of spinal vascular malformations with syringohydromyelia has been scarcely reported $[4,5]$ and only in the adult population.

MRI in a case of PMAVF usually shows cord expansion with long segment $\mathrm{T} 2$ hyper intensity, owing to venous congestion which can eventually progress to necrosis of the cord, resulting in syrinx formation. DSA is considered to be the gold standard in evaluating the SCAVM and its further classification [1].

The association of PMAVF with syringohydromyelia, expanded cord with intramedullary T2 hyperintensity and low lying tethered cord with spontaneous clinical and radiological resolution of the syrinx and myelopathy over a period of 2 months has not been previously described in the literature.

\section{Case report}

A 6 year old male child presented with rapidly progressing weakness of both the lower limbs. Initially it started with difficulty in putting on the slippers and within a period of 3 weeks, the child was unable to stand or walk without support. There was no sensory loss or bladder and bowel dysfunction. On examination the power was grade $2 / 5$ in both the lower limbs.

Correspondence to: Vivek Singh, Department of Radiology, Sanjay Gandhi Post Graduate Institute of Medical Sciences (SGPGIMS), Rae Bareli Road, Lucknow-226014, Uttar Pradesh, India, Tel: 8004904503, E-mail: singhvivek79@ rediffmail.com

Key words: Perimedullary arteriovenous fistula, spinal cord arteriovenous malformation, syringohydromyelia, syrinx, tethered cord, spontaneous resolution

Received: June 25, 2017; Accepted: July 24, 2017; Published: July 27, 2017 

cord

MRI scan of his spine revealed low lying tethered cord (lower border at the level of S3) with cord expansion and extensive septated syringohydromyelia, extending from the lower border of D7 to S3 level. Long segment T2 hyperintensity was noted in the upper dorsal cord, above the syrinx Prominent flow voids were noted in the perimedullary regions, predominantly on the ventral aspect of the cord (Figure 1). No intramedullary flow voids were seen. There was no enhancement of the cord or the syrinx on post contrast study (Figure 2). No features of spinal dysraphism or Chiari malformation were noted. Based on the MRI findings a provisional diagnosis of spinal vascular malformation was made and a diagnostic spinal Digital subtraction angiography (DSA) was done.

DSA showed a type IVA PMAVF, with a single arterial feeder (Anterior spinal artery), arising from the left D9 intercostal artery, with fistula at the level of lower border of L3. Mildly dilated and tortuous perimedullary draining vein was noted which subsequently was seen to drain into the left internal iliac vein (Figure 3). No venous ectasia/ varix was seen. The child was then managed conservatively with advice for follow up after 8 weeks to plan for subsequent intervention and treatment.

To our surprise, when the child returned after 8 weeks, he was able to walk on his own with occasional assistance of his parents. The power in both the lower limbs had improved to grade 4/5. A non-contrast MRI study of the spine revealed marked spontaneous resolution of the syrinx in the dorsal region (Figure 4). The dorsal cord had returned to its normal calibre. Residual mild intramedullary T2 hyperintensity was seen in the upper dorsal cord. Focal small residual syrinx was noted in the lumbo-sacral region with persistence of the prominent perimedullary flow voids (predominantly ventral). The child is currently on follow up with plan for subsequent intervention based on the clinical status.

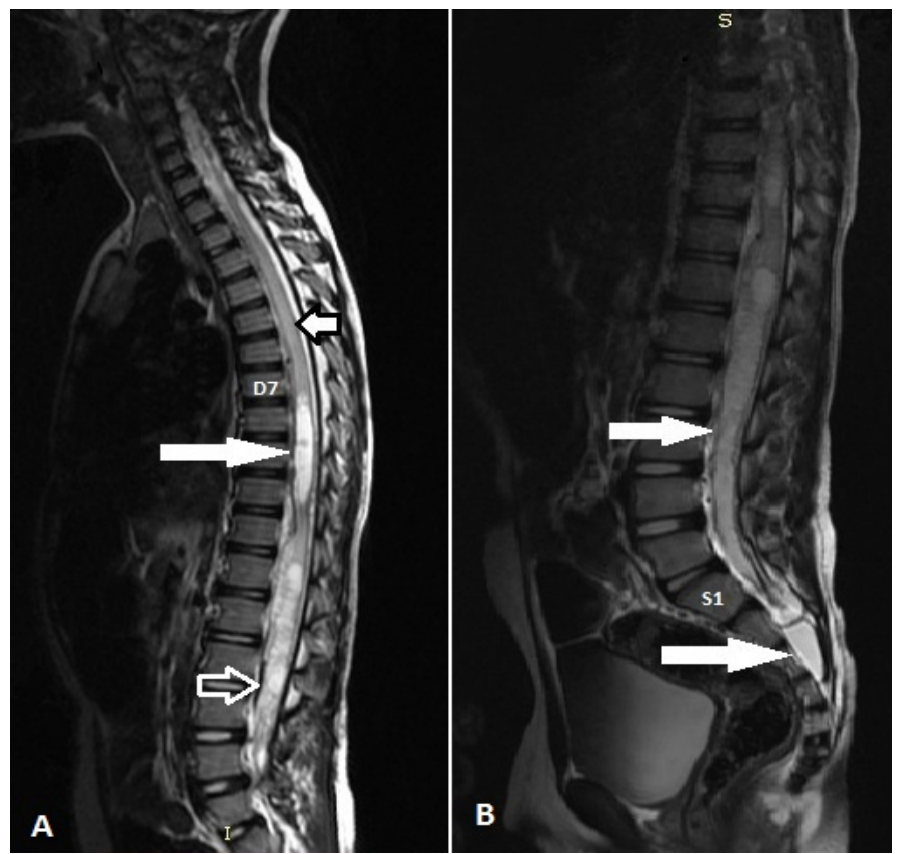

Figure 1. A: Sagittal T2W (TR/TE, 4000/120 ms) image shows the expanded cord with long segment syringohydromyelia extending from lower border of D7 to S3 (long white arrows) B: Long segment $\mathrm{T} 2$ hyperintensity is noted in the dorsal cord above the syrinx (short white arrow). Prominent flow void is noted at the anterior surface of cord in the lower lumbar region (hollow white arrow) Figure 1A.
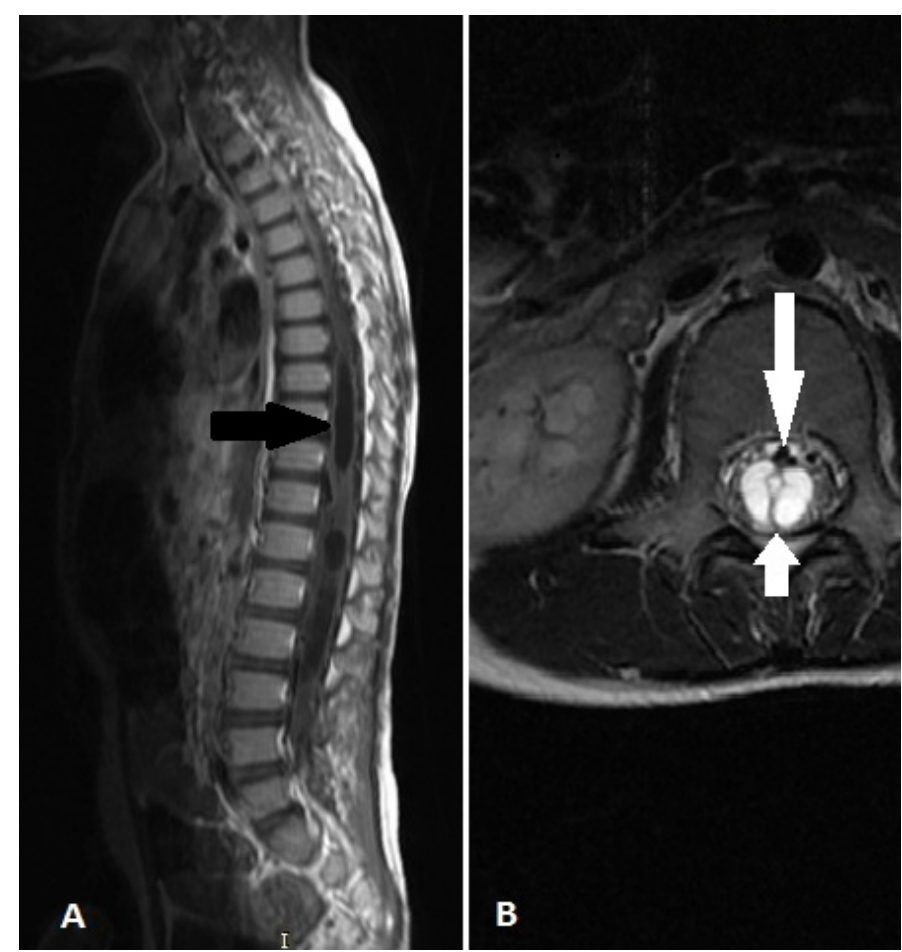

Figure 2. A: Post contrast Sagittal T1W (TR/TE, 800/30 ms) image showing the non enhancing syrinx (black arrow). B: Axial T2W (TR/TE, 5000/130 ms) image showing the expanded cord with septated syrinx (short white arrow) and prominent rounded intradural flow voids at the ventral aspect of the cord (long white arrow).
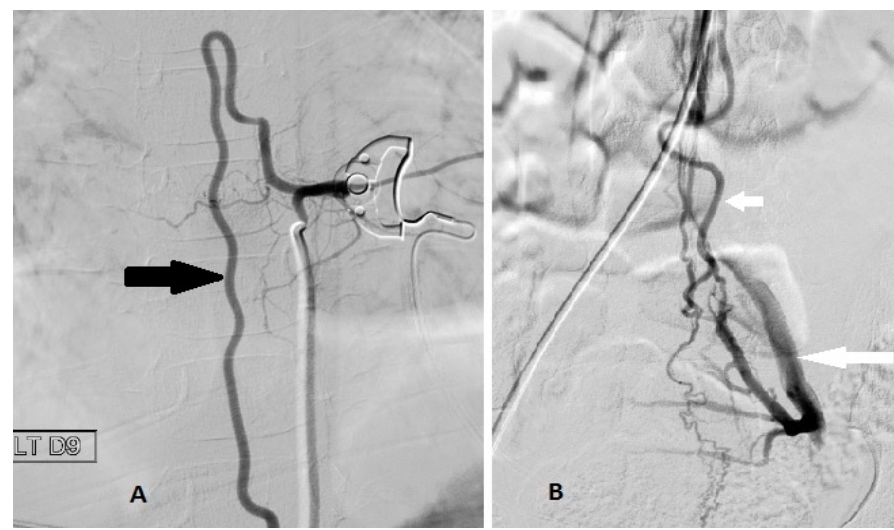

Figure 3. A: DSA image showing the enlarged, dilated and tortuous anterior spinal artery with its characteristic hair pin bend (black arrow), arising from the left D9 intercostal artery. B: DSA image showing the site of arteriovenous fistula (blue arrow) with descending dilated lower end of anterior spinal artery (short white arrow) and draining vein which is seen to finally drain into the left internal iliac vein (long white arrow).

\section{Discussion}

Vascular malformations of the spinal cord are rare, and their classification and treatment is complex [6]. First described by Djindijan in 1977, PMAVFs are also known as Intradural ventral AVF [1] PMAVFs have been classified into 3 subtypes (A,B and C) by Anson and Spetzler in 1992. Type IVA consists of small and slowly flowing fistulas, fed by single artery, usually the ASA, Type IVB consists of larger fistulas with one or more dilated arterial feeders, supplied by either the ASA and/or the PSA. Type IVC is nourished by multiple dilated arteries, with extremely rapid flow in the fistula and with giant dilated and ecstatic veins. The most frequent of the type IV SCAVMs are types IVB and IVC [1]. 

cord
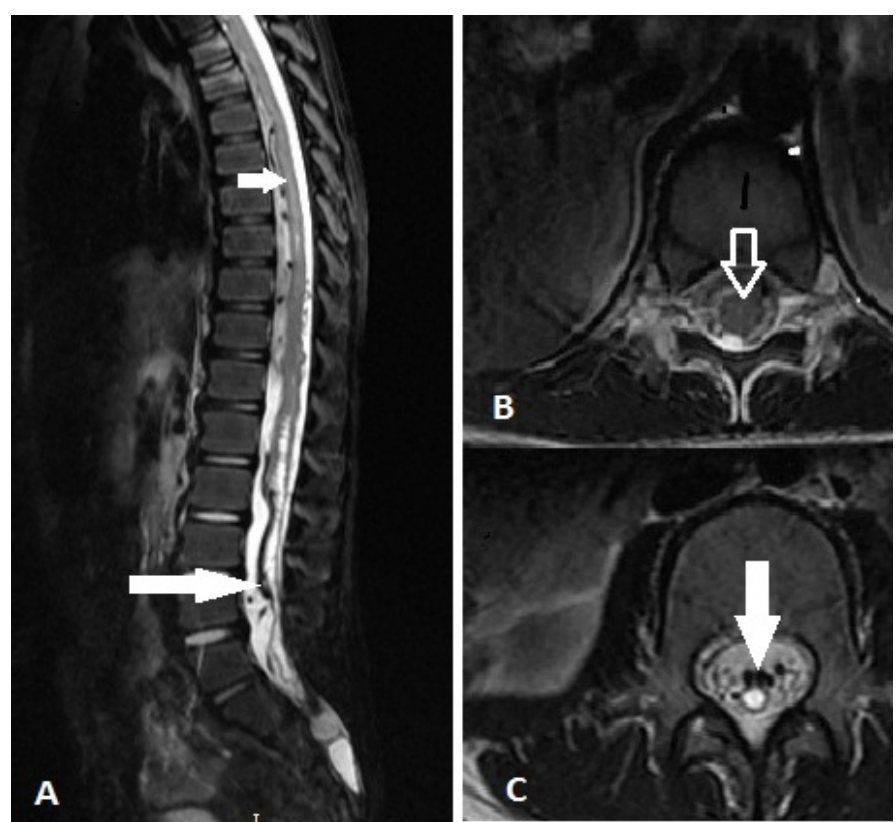

Figure 4. A: Sagittal T2W (TR/TE , 4000/120 ms) image done 2 months later showing the marked resolution of syrinx in the dorsal cord with mild intramedullary $\mathrm{T} 2$ hyperintensity in the upper aspect of the dorsal cord (small white arrow). Prominent flow voids are noted intradurally at the ventral surface of the cord (long white arrow). B: Axial T2W (TR/TE, $5000 / 130 \mathrm{~ms}$ ) image showing the normal caliber dorsal cord with resolution of the syrinx (long white arrow). Figure 4C- Axial T2W (TR/TE, 5000/130 ms) image at the lumbar region showing small residual syrinx (hollow white arrow) with few ventral perimedullary flow voids (long white arrow).

The mean age of presentation PMAVFs has been found to range from 19.5 to 45 years PMAVFs are reported relatively rarely in children. The estimated prevalence of PMAVFs in the paediatric population is around $0.5 \%$ to $3.25 \%$ [1]. Rodesch et al. pointed out that the majority of lesions affect the males.

These lesions can occur anywhere along the spinal axis but most commonly in the thoracolumbar region, particularly at the conus medullaris. They are most often located ventrally at the level of the conus medullaris or cauda equine [1]. Although the etiology is not clear, there are well-documented cases of both congenital and acquired PMAVFs.

Patients with PMAVF usually have progressive or fluctuating neurological dysfunction. In the paediatric age group these generally tend to present acutely with a higher incidence of subarachnoid haemorrhage. Venous hypertension tends to be associated with spinal AVFs and is most likely responsible for development of progressive myeloradiculopathy. Other proposed pathological basis includes haemorrhage, secondary to rupture of a feeder artery or ectatic venous sac, and the mass effect from large draining veins and varices [1].

Congestive myelopathy may occur with vasogenic edema, which may progress to subacute necrotizing myelopathy, also known as Foix-Alajouanine syndrome [1], characterised histopathologically by necrosis of the spinal cord and numerous thickened tortuous vessels lying on the surface of the cord [7]. These can explain the imaging appearance of the intramedullary $\mathrm{T} 2$ hyperintensity and syrinx formation in the cord. However there is scarcity of literature regarding the association between PMAVF and hydrosyringomyelia.

Irrespective of the location of the fistula it is the lower part of the cord that is affected commonly and shows signal changes on MRI. Two reasons are put forward to this phenomenon- (a) the intraspinal venous system is valve less and due to gravity the lower part of the cord is more congested and (b) the collateral outflow from the lower part of the dorsal cord is less even in normal subjects and this leads to impaired dissipation of venous hypertension found in patients with AVFs [8].

Srivatanakul et al. [4] have described 4 cases of syringomyeliaassociated spinal cord arteriovenous malformation (AVM) in which the the syringomyelia resolved after embolisation of the AVM. Reports concerning AVM as a cause of syringomyelia is very scarce and lacks posttreatment clinical information.

Hasegawa et al. have reported another case of spinal arteriovenous malformation associated with syringomyelia extended over the entire spinal cord that presented mainly as spastic paraparesis. They have concluded that vascular malformation is a rare cause of secondary Syringomyelia [5]. However association of syringohydromyelia in a case of type IVA PMAVF has also not been reported till date.

The association of PMAVF with tethered spinal cord has been previously reported by Hurst et al. [9]. Spontaneous resolution of syrinx in cases of Chiari malformation have been described in literature [2] and so has been spontaneous resolution of spinal dural AV fistulas (AVF) and epidural AVF. Resolution of syrinx following surgical treatment or embolisation is also well documented [4].

However self-resolution of syrinx in the dorsal cord with normalization of the cord calibre in cases of PMAVF has not been described in literature till date. We assume this to be due to spontaneous opening up of congested and thrombosed intra and perimedullary veins in the dorsal cord with subsequent clearance of the venous congestion. In our case the main venous drainage as seen in DSA was in a descending manner via the left internal iliac vein, no significant size ascending venous structures could be seen, this leads to a suspicion that thrombosis of some of these channels might have led to these syrinx formation and spontaneous opening of which have led to disappearance of these. However we didn't repeat the DSA and there is no literature to support our assumption.

To conclude, the amalgamation of Type IVA PMAVF with low lying tethered and expanded cord with extensive syringohydromyelia and intramedullary T2 hyperintensity in a 6 year old male child is indeed rare. Furthermore spontaneous resolution of the syrinx with normalization of the calibre of the dorsal cord over a span of 2 months has not been described previously in literature and has thus prompted us to report this very rare entity.

\section{References}

1. Matushita H, Guilherme J, Caldas MP, Texeira MJ (2012) Perimedullary arteriovenous fistulas in children: reporton six cases. Childs Nerv Syst 28: 253-264

2. Deniz FE, Oksüz E (2009) Spontaneous Syringomyelia Resolution at an Adult Chiari Type 1 Malformation. Turk Neurosurg 19: 96-98. [Crossref]

3. Unsinn KM, Geley T, Freund MC, Gassner I (2000) US of the spinal cord in newborns spectrum of normal findings, variants, congenital anomalies, and acquired diseases. Radiographics 20: 923-938. [Crossref]

4. Srivatanakul K, Songsaeng D, Ozanne A, Toulgoat F, Lasjaunias P (2009) Spina arteriovenous malformation associated with Syringomyelia. J Neurosurg Spine 10 436-442. [Crossref]

5. Hasegawa O, Suzuki Y, Nagatomo $\mathrm{H}$ (1991) A case of spinal arteriovenous malformation associated with syringomyelia extended over the entire spinal cord that presented mainly as spastic paraparesis. Rinsho Shinkeigaku 31: 653-357. [Crossref]

6. Sure U, Wakat JP, Gatscher S, Becker R, Bien S, et al. (2000) Spinal type IV arteriovenous malformations (perimedullary fistulas) in children. Child's Nerv Syst 16 508-515. [Crossref]

7. Kelly C (2005) Foix-Alajouanine syndrome: case report. Arq Neuropsiquiatr 63: 527-529 
Singh V (2017) Spontaneous resolution of syringohydromyelia in a case of spinal Perimedullary Arteriovenous fistula (Type IVA) associated with low lying tethered cord

8. Krishnan P, Banerjee TK, Saha M (2013) Congestive myelopathy (Foix-Alajouanine Syndrome) due to intradural arteriovenous fistula of the filum terminale fed by anterior spinal artery: Case report and review of literature. Ann Indian Acad Neurol 16: 432436. [Crossref]
9. Hurst RW, Bagley LJ, Marcotte P, Schut L, Flamm ES (1999) Spinal cord arteriovenous fistulas involving the conus medularis: presentation, management, and embryologic considerations. Surg Neurol 52: 95-99. [Crossref]

Copyright: (C2017 Singh V. This is an open-access article distributed under the terms of the Creative Commons Attribution License, which permits unrestricted use, distribution, and reproduction in any medium, provided the original author and source are credited. 